\title{
ZUM-ZUM-ZUM: ESTUDO SOBRE O NOME CONTEMPORÂNEO
}

\author{
LIONEL RUFFEL repensa os desdobramentos do conceito na \\ atualidade
}

Em maio de 2012, a Universidade Stanford organizou um colóquio intitulado “¿Qué es lo contemporáneo? O que é o contemporâneo? What is the contemporary?”. Essa questão, “O que é o contemporâneo?”, que, até 2004, nunca havia sido colocada nesses termos, foi então objeto de uma retomada, visto que ecoava pela oitava vez em oito anos. $\mathrm{Na}$ primeira vez, foi colocada em uma série de artigos publicos na revista Zum, do Centro de Expresiones Contemporáneas (Rosário, Argentina); na segunda, foi em Veneza por Giorgio Agamben; depois, foi colocada duas vezes na França, em Rouen, por um coletivo de arquitetos, em Partin, por literatos e filósofos; ela retornou à Itália durante um colóquio consagrado às artes cênicas; finalmente, foi colocada duas vezes em 2011 em Santiago (Chile), por historiadores e especialistas em cultural studies, e em Bruxelas, pela revista Pylône, de maneira interligada e interdisciplinar. Um número da norte-americana Revista de Estudios Hispánicos não tardou a ser publicado com esse título, sendo realizada uma conferência em St. Andrews, na Escócia, em que o contemporâneo pareceu suscitar uma interrogação infinita.

Essa série não resolvida nos diz duas coisas que podem parecer contraditórias.

Por um lado, marca o fim de um processo de substantivação. $O$ "contemporâneo" não é mais um simples adjetivo qualificador de sujeitos, de objetos ou de uma época; um adjetivo que foi por muito tempo zombado por sua falta de densidade e consistência se tornou um substantivo cuja própria substância passou a ser questionada. Com a sensação intuitiva de que ele nos diz respeito coletivamente. Por outro lado, embora essa série marque o fim do processo de substantivação, é preciso observar que esse fim é inacabado ou, pelo menos, inacabável. 
Afinal, o que incomoda é a retomada exata da mesma fórmula inquisitiva que assinala o fracasso de toda tentativa de determinação unívoca.

O contemporâneo, ao contrário de outras categorias, nunca havia até então sido objeto de um fenômeno de questionamento em massa. Naturalmente, a arte contemporânea, a dança contemporânea e a música contemporânea suscitaram debates inflamados, mas, no fundo, não era o contemporâneo que estava sendo questionado, mas sim os substantivos que ele qualificava (arte, dança ou música) e a modificação que houve neles. A noção, a categoria e o conceito foram impostos sem serem realmente questionados. Como se fosse natural que estivessem ali agora. Há, portanto, um contraste impressionante entre esse período relativamente longo durante o qual o contemporâneo se impôs sob debates muito mais barulhentos (como aquele sobre o pós-moderno) e essa série de questionamentos recentes a respeito de sua identidade.

\section{A HIPÓTESE ESTÉTICA}

Não prevejo o retorno de uma ambiguidade que considero já esquecida. Enquanto durante muitos séculos, o contemporâneo bastou a si mesmo ao significar a copresença no tempo que passa, condenado a sofrer sua fugacidade e não significar nada mais do que uma forma de atualidade reduzida ao efêmero, ele passou a ser inscrito (como qualificativo) nas fachadas de museus, nos títulos de cursos, funções e especialidades universitárias. Ele dialoga, assim, com outras categorias (antigo, clássico, moderno) consideradas, a priori, como sérias ou, ao menos, consistentes. Ao contrário, por exemplo, do pós-moderno, que nunca foi tema de uma inscrição institucional e disciplinar e só existe de forma marginal em museus de arte pós-moderna ou professores de história pós-moderna. Apesar disso, existe ainda em revistas acadêmicas com esse nome, como a Postmoderne Culture, que não sabemos hoje se tem um objetivo histórico ou o compreender a atualidade. O que é significativo é que, para festejar seus 20 anos, ela organizou, em outubro de 2010, um colóquio intitulado "Culture After Postmodern Culture".

Caso ainda seja necessáro, um único exemplo permite invalidar a hipótese da simples fugacidade do contemporâneo. Como boa parte dos museus de arte contemporânea tem e trabalha a partir de uma coleção, 
eles também têm uma visão histórica, arquivista e documental, que não pode ser reduzida à simples função de mostrar a arte de um hoje em constante mudança. O contemporâneo é, portanto, um conceito, ao menos em parte, histórico.

Mas é também um conceito com uma história.

Em outros artigos [1], tentei descrever de maneira muito sintética as duas primeiras etapas dessa história (ou melhor, dessa story): a aparição e a imposição.

Tomei muito cuidado ao tentar retraçar a história de uma palavra, consciente de que só podemos historicizar a partir dos usos lexicais. Tomei tal precaução porque escrevia minha pesquisa muito modestamente na esteira da pesquisa de H. R. Jauss sobre a aparição e as metamorfoses da palavra modernidade[2], que serviu de matriz para o estudo de todas as categorias estéticas.

De certa forma, esse estudo, guiado pela hipótese de que o contemporâneo é uma característica estética, poderia se chamar, plagiando o título de Jauss, “O 'contemporâneo' na tradição estética e na consciência da atualidade”. O texto de Jauss é quase insuperável; são inúmeras as suas contribuições. Dentre elas, podemos usar a ideia de que existe uma consciência histórica variável ou relativa do presente, mais ou menos intensa, e que os momentos de grande intensidade se caracterizam pela formação ou reativação de uma palavra. Embora Jauss não o diga, podemos inferir a partir de seu estudo que o grau de intensidade pode ser medido pela utilização ou reativação de uma palavra que decorra também da temporalidade. Entre elas: "Antiguidade", "antigo", "Renascimento", "moderno", "modernidade". Segundo Jauss, esses momentos são muito raros. Eles assinalam a formação de uma identidade histórica, isto é, um momento em que a relação entre experiência estética, política e histórica se cristaliza em uma palavra. O contemporâneo substantivado atende a todos esses critérios. Construído sobre uma palavra derivada da temporalidade histórica, assinala um momento de grande intensidade na consciência histórica do presente. Passa a ser necessário, portanto, compreender o que ele nos diz. 
Seguindo o exemplo de Jauss, em um primeiro momento me interessei pela história da palavra "contemporâneo", lembrando que, em francês, assim como na maior parte das línguas latinas e no inglês, é uma palavra de uso recente. Originada do latim medieval, contemporaneus, que significa "do mesmo tempo", ela aparece na forma atual durante o século $\mathrm{XV}$ e, depois, apresenta três expansões de uso que correspondem a três momentos de crises filosófica e estética na Europa (Renascimento, Querela dos Antigos e dos Modernos e Iluminismo). Apesar desses momentos de expansão, seu uso era limitado, tanto em extensão como em sentido, especialmente porque se deu preferência a uma palavra muito mais antiga, muito mais tradicional e, em certo aspecto, muito mais carregada semanticamente: moderno. De certo ponto de vista, $o$ "moderno" sempre designou a novidade trazida por um presente em relação à antiquitas.

Faltava, então, tentar compreender porque hoje o termo moderno quase não é utilizado, ao passo que o contemporâneo tomou o discurso sobre a representação do presente histórico. Nesse ponto também segui o exemplo de Jauss, traçando um paralelo entre o uso da língua, da experiência estética e da experiência histórica. Como a palavra contemporâneo ganha consistência e surge como conceito-chave após a Segunda Guerra Mundial, só nos resta ver essa passagem do moderno para o contemporâneo a partir das transformações profundas que então afetaram o mundo. Quatro delas são notáveis e, juntas, caminham no sentido de enaltecer o "contemporâneo".

O primeiro desses parâmetros é, ao mesmo tempo, demográfico, político e cultural. Após a Segunda Guerra, o mundo ocidental, então detentor de capitais econômicos e simbólicos, viu uma mudança demográfica sem precedentes, o famoso baby boom, que representou uma democratização e uma massificação do acesso ao conhecimento, à cultura e à criação. Trocando a erudição pela experiência e pela prática, uma nova geração toma o poder de maneira inexorável e busca se nomear de outro modo. Paralelamente, a cartografia intelectual e cultural do mundo se modifica e se descentraliza: num primeiro momento, passa a se equilibrar do outro lado do Atlântico; em um segundo momento, mais recente, se “policentraliza”, particularmente durante o "período” pós-colonial. 
Surgem visibilidades artísticas e intelectuais inéditas, provenientes de regiões antes dominadas, propondo uma imagem do presente que a já batida palavra modernidade não é mais capaz de englobar. Melhor dizendo, essa imagem do presente contesta exatamente os pontos da modernidade, em especial o eurocentrismo e, de modo mais geral, sua tendência a privilegiar a maioria em detrimento da minoria.

Paralelamente, houve uma guerra $e$ uma disputa sem as quais essa época não teria conseguido se tornar visível ou impor sua diferença. Já na década de 1980, nos Estados Unidos, irrompe uma guerra de cânones literários, demonstrando que toda tradição é inventada e toda comunidade imaginada, especialmente as tradições e comunidades nacionais. O ensino da literatura e dos "grandes textos" formava um dos pilares essenciais dessa educação que caracterizava a modernidade em nível nacional. Consideremos, então, as consequências de seu desmoronamento, que assinala a introdução de temas contemporâneos na formação (escolar e universitária).

Quanto à disputa, foi a célebre "querela da arte contemporânea”. Vinte anos depois, o que resta dela? Uma reflexão apaixonante sobre a estruturação do espaço artístico. O que expor? Onde expor? Para que público? Para que relação entre artista, produtor e aqueles que entram nos espaços de exposição? As reflexões sobre arte contemporânea (em primeiro plano, aquelas que os artistas suscitaram com suas proposições) poderiam inspirar outros campos do conhecimento e da cultura, visto que foram precisamente elas quem conseguiram pensar essa mudança demográfica, política e cultural.

Portanto, do ponto de vista da temporalidade histórica - e apenas desse ponto de vista, que é especialmente problemático e será muito contestado - pode-se chegar a uma sequência quase coerente que impõe (ou acompanha) a necessidade de se recorrer a um novo termo. Esse momento contemporâneo, que nasce na segunda metade do século XX, se caracteriza em grande parte pelo uso do termo contemporâneo para designar-se, embora sua definição possa parecer enganosa. Este termo, longe de ter um sentido vazio, marca uma série de transformações importantes que dialetizam certos princípios da modernidade ao mesmo 
tempo em que recusam os fundamentos da consciência moderna.

Se ele não recusa os fundamentos é porque, ao contrário do que se poderia pensar à primeira vista, "moderno" e "contemporâneo" não se situam no mesmo plano e, portanto, não se opõem um ao outro. Segundo Jauss, existe, desde o fim do Império Romano, uma oposição estruturante e estrutural na consciência histórica entre antigo e novo ou, melhor dizendo, entre antigo e moderno. $\mathrm{O}$ antigo e o moderno mudam com o tempo, assim como a natureza de sua oposição. Eles às vezes encarnam uma série de palavras que constituem um segundo nível na representação histórica do presente. De um lado, podemos encontrar o "antigo" ou "clássico"; do outro, variações do moderno, como "modernidade" ou "modernismo" ou ainda "romantismo" - o ensaio de Jauss é significativo nesse sentido. Há, segundo ele, um terceiro nível, constituído por movimentos artísticos ou tendências políticas. A hipótese estética sustenta que o "contemporâneo" é um termo de segundo nível, inteiramente comparável, por exemplo, a "romantismo" ou "modernidade", tal como Jauss os analisa. Nesse sentido, ele seria uma forma de moderno, como o Renascimento, o Romantismo ou a modernidade foram.

\section{QUATRO ABORDAGENS}

A narrativa que permite chegar a essa hipótese é, porém, muito rápida e tem algo de peremptório. Ela não é falsa, mas lhe falta sutileza ao tentar expor três ou quatro grandes parâmetros determinantes, enquanto, na verdade, são os microfenômenos que importam mais. Portanto, mais do que uma história do contemporâneo, trata-se de uma story que se lê, ou seja, um dos métodos menos atuais ou contemporâneos das ciências humanas.

Além disso, para chegar a essa hipótese, faltou sobrepor quatro níveis de compreensão de categorias estéticas que convém agora distinguir, mesmo que nenhuma exista sem as outras. Afinal, existem ao menos quatro formas de se entender o contemporâneo.

O primeiro nível de compreensão, o mais direto e fácil, mas também o menos convincente e mais discutível, é relativo à abordagem epocal[3]. 
Nesse sentido, o contemporâneo será uma época - no caso, "nossa" época, pois só ela o reivindica como critério de identificação coletiva. Contudo, esse "nossa" gera um problema. O mundo "contemporâneo" (no sentido epocal) é atravessado por tantas realidades diversas e contraditórias que invalidam quase toda a possibilidade de "nossa". O "nossa" abrangente só é reutilizado com a condição de gerar imperialismo ou egocentrismo. Imperialismo porque se trata de incluir o conjunto de fenômenos coletivos em uma representação situada, dos pontos de vista geográfico e temporal. Egocentrismo porque implica em situar o conjunto desses fenômenos em torno de uma pessoa. Dessa forma, grande parte da crítica cultural e estética só pode agir de maneira diferente no tempo em que vivia os fenômenos ou grandes rupturas, simplesmente porque participava deles. Esse é o egocentrismo.

Paralelamente, de um ponto de vista epistemológico, a abordagem epocal coloca o problema da periodização e, portanto, de uma representação limitada pelo tempo. Mas a experência deveria nos encorajar a desconfiar da periodização. Uma disciplina histórica - o que não é pouco, pois se trata da própria história - se serviu, muito mais do que as outras, da categoria do contemporâneo. Na representação tradicional que dá ao tempo histórico (sujeita a inúmeras críticas internas já clássicas), ela reúne quatro grandes períodos: a história antiga, a história medieval, a história moderna e a história contemporânea. Para esta última, colocamse os problemas desses dois limites. Onde ela começa? Onde termina? E será que termina de fato? Todas as soluções consideradas eram fracas. De um lado, porque o primeiro reflexo foi o de estabelecer limites segundo as histórias das nações, tendo como início do período contemporâneo 1789, 1914, 1917 e até 1945. Mais uma vez, encontramos o egocentrismo. De outro lado, porque o reflexo foi estabelecer limites em razão de grandes acontecimentos. No entanto, toda a historiografia contemporânea criticou essa abordagem através de grandes eventos, assim como a história literária e a história da arte relativizaram com muita firmeza uma leitura através de grandes obras ou grandes autores. Essas noções - grandes acontecimentos, grandes autores, grandes obras - têm origem em uma maneira lendária de compreender a história e costumam funcionar como reconstruções a posteriori. Por fim, colocou-se a questão de saber se um período poderia estar em curso ou se era 
preciso limitar seu fechamento. Para responder a essa questão, era preciso esclarecer um quinto período, a história do tempo presente, que, embora problematize o conjunto dessa representação sequencial, não foge dela. Uma consequência é que, se seguirmos o exemplo da história, o período contemporâneo pertence ao passado. Outra é que esse modelo não estruturou o conjunto de disciplinas, visto que nenhuma ciência humana ou social a retomou. Por outro lado, a abordagem epocal, tão firmemente ancorada na história das representações (que pensamos em suas variações precedentes na forma de ciclos ou eras), ainda que problemática, continua a assombrar nossa representação do tempo e, portanto, do contemporâneo. É por isso que pude, no argumento inicial, evocar o período posterior à Segunda Guerra.

A segunda abordagem pode ser chamada de modal. O contemporâneo é uma relação com o tempo histórico, um modo de ser no tempo. Ele é, portanto, trans-histórico. Haveria tantos contemporâneos quanto houve momentos históricos, que foram contemporâneos um após o outro. $\mathrm{O}$ contemporâneo designa, portanto, uma relação com o tempo, a história e a atualidade, qualquer que seja a época. Basta lembrar, como falamos às vezes, que tal e tal pintor foram contemporâneos em seu tempo para chegar a essa evidência. Para essa concepção, seria mais correto falar de contemporaneidade do que de contemporâneo. Por mais que essa abordagem possa ser maximalista demais para nos permitir entender o que é o contemporâneo, ela é muito mais substancial do que a primeira. Partindo do pressuposto de que existe uma razão ou um conjunto de razões que levaram uma coletividade a se designar pelo termo contemporâneo, a insistência sobre um modo de ser será certamente produtiva.

Ela corre o risco, porém, de cair no essencialismo se não a associarmos a duas outras abordagens que dialogam entre si e têm claramente a minha predileção, ao menos como portas de entrada. De um lado, está a abordagem nocional: o contemporâneo é uma noção e, como todas as noções, é fruto de uma criação que tem sua própria história. E, como todas as histórias, ela pode ser retraçada desde que pensemos nela como um evento de discurso. O contemporâneo resulta de um conjunto de discursos que se cruzam, que respondem uns aos outros, que se 
superpõem e que se diferenciam. É preciso, portanto, estar atento a esse evento do discurso para compreendermos o que ele significa. A quarta abordagem é um subgrupo da anterior: trata-se de uma abordagem institucional. É uma porta de entrada mais fácil, exatamente por sua visibilidade. Pensemos, por exemplo, na instituição dos museus, que inscrevem na pedra de certas fachadas a palavra contemporâneo. A multiplicação dessas instituições em todo o mundo nos faz entender melhor como se constitui um imaginário do contemporâneo e que forma ele assume.

Essas quatro abordagens - às quais convém acrescentar a hipótese do contemporâneo como categoria estética -, longe de serem exclusivas, se alternam e se superpõem, e é preciso tentar entendê-las como um todo.

\section{O QUE O CONTEMPORÂNEO PODE DIZER}

Uma story, quatro abordagens e diversas hipóteses já são muita coisa. Ainda mais considerando que nenhuma nos diz realmente por que esse termo se impôs, como age e como age sobre nós. Pois, embora queiramos tirar na narrativa anterior que é justificável uma nova atualização de moderno, não há nenhuma razão a priori para que ela prefira a palavra contemporâneo. As categorias costumam ser chamadas por palavras que, em si, dizem alguma coisa. Para compreendê-la, é preciso antes saber quem as enuncia. Deve-se, portanto, distinguir as categorias impostas $a$ posteriori pela história e aquelas que os próprios atores parecem ter escolhido: alodefinitório ou autodefinitório. O contemporâneo é uma categoria autodefinitória, usada por seus próprios atores. Não exatamente reivindicada ou anunciada. Mas, ao mesmo tempo, muitíssimo usada. Num caso como esse, um instinto nos leva a crer que a autodefinição produz sentido. E, como esses termos, segundo Jauss, quase sempre vieram do vocabulário temporal, nosso instinto nos leva a pensar que essas categorias determinam uma relação com o tempo. Isso não é nem um pouco evidente. $\mathrm{O}$ uso de categorias que uma comunidade utiliza para se designar pode ser puramente casual. Essas duas possibilidades (significação clara ou puro acaso) estão longe de serem contraditórias e há uma circulação permanente entre usos múltiplos, casuais e contraditórios de categorias e tentativas de semantização. Podemos simplesmente contrastar que mundos de uma diversidade 
muito grande vão aos poucos se reconhecendo distinta e mutuamente em uma palavra que, do ponto de vista lexical, diz alguma coisa.

"Com o tempo", "que existe ao mesmo tempo".

Mas o que significa "com o tempo"?

Há uma primeira forma de entender esse "com o tempo". Essa fórmula considera principalmente a questão do presente. Com o tempo significa estar no presente. Mas o que é exatamente estar no presente? No fundo, tudo depende do regime de historicidade. Parte da historiografia trabalha já há muito na semântica do tempo. Para Reinhardt Koselleck e, depois, François Hartog, o tempo não é um envelope vazio - ele é preenchido pelos sujeitos que o vivenciam. A articulação entre passado, presente e futuro a partir do presente resulta de uma tensão entre o campo da experiência e o horizonte da espera. Para seguirmos, ainda que de maneira muito resumida, o pensamento de François Hartog, podemos distinguir (pelo menos) três regimes históricos, ou seja, três maneiras de ser segundo as quais o horizonte de espera se situa no passado (como nos mitos da Idade do Ouro ou do paraíso perdido), no futuro (o progresso, a novidade) ou no presente. O ensaio de François Hartog mostra que, aos poucos, uma crise do tempo vai se instalando no decorrer do século XX e é radicalizada no XXI, a qual nos faz passar de um regime muito futurista a um mais presentista, no qual o centro de gravidade de nosso tempo é o presente. Ele fala então da "experiência contemporânea de um presente perpétuo, inacessível e praticamente imóvel, que busca, contra todas as forças em contrário, produzir seu próprio tempo histórico para si mesmo. Tudo acontece, aliás, como se não houvesse nada além de presente, uma espécie de vasta extensão de água que agita um sussurro incessante" [4]. Mais precisamente ainda: "É esse momento e essa experiência contemporânea do tempo que chamo de presentismo".

Como a palavra "presentismo", talvez por lhe faltar precisão historiográfica, não foi retomada pelo discurso comum, desejo reformular essa frase para incluí-la em uma proposição quase tautológica: "É esse momento e essa experiência contemporânea do tempo que a palavra contemporâneo designa". 
É preciso recorrer a uma segunda interpretação do que o contemporâneo pode significar. A contemporaneidade poderia ser compreendida como uma cotemporalidade, como uma concordância de tempos múltiplos. Sempre encontro, especialmente em obras de arte, mas também na teoria crítica, uma representação palimpséstica ou múltipla do tempo em que o presente não é uma sequência temporal, mas um ponto de metabolização de todos os passados e futuros. "O que é do mesmo tempo" não remeteria necessariamente a essa confraternidade de época, mas à contemporaneidade, no presente, de todos os tempos históricos. É claramente uma visão benjaminiana de história que se impõe em todos os campos de representação e que poderia muito bem encontrar sua semantização mais exata na palavra contemporâneo.

Mas “com o tempo" significa também outra coisa. Há no cum- um acordo, um acompanhamento, uma adesão que não aparece tão claramente nas línguas que não o utilizam mais como preposição ou advérbio. É preciso fazer uma comparação linguística para entender melhor. Por exemplo, o alemão é mais preciso. Zeitgenössisch, "contemporâneo", associa Zeit e Genosse, tempo e companheirismo, camaradagem. Ser um camarada de tempo, um companheiro de tempo, é uma ideia problemática, muito zombada nas representações teóricas e artísticas. Afinal, é evidente que, nas teorias modernas, a subjetividade individual ou coletiva é necessariamente contrária. É preciso matar o pai, opor-se à mãe, lutar contra a sociedade. As próprias expressões artísticas costumam ser as mais pensadas nessa lógica oposicional. Os malditos, os recusados, são (com razão) os mais valorizados. E disso retemos principalmente que eles foram malditos, recusados. Ninguém teria sido um bom camarada ou um bom companheiro de tempo. Nessa lógica, os camaradas de tempo são os oficiais, os resignados. Será que passamos a uma lógica inversa? Uma lógica de adesão máxima, de consentimento. Essa ideia atravessa o campo intelectual, de um polo conservador, que reivindica uma descontemporaneidade, ridicularizando os "descontentes com tudo", que só veem uma postura ética no ódio à época (a qual muito os prejudica, reservando-lhe todas as posições de honra, todos os privilégios econômicos e simbólicos, ao menos em um país antigo como a França) a um polo emancipador que narra os tempos consensuais e enuncia o fim dessa discordância necessária à política. Sobre o primeiro 
polo, não há mais nada a dizer. Como a postura reacionária defende a lógica oposicional, a confusão política fica à espreita. O segundo é muito mais matizado, muito mais sutil, e é muitas vezes ele que nos permite entender o que poderia ser um companheirismo temporal.

Encontrei a formulação mais exata desse companheirismo em um texto literário ou, melhor, em uma espécie de arte poética da escritora Emmanuelle Pireyre, intitulada "Fictions documentaires"[5].É possível dizer que, em termos de postura, nada a distingue da lógica oposicional. Por outro lado, ela não para de usar o vocabulário do cum-, da relação. Assim, postula que "existe uma relação próxima entre o tipo de produto literário de uma certa época e seu contexto histórico e social, segundo a forma como os textos escolhem seu lugar de enunciação, o terreno de onde falam". Em seguida, multiplica os termos que remetem ao companheirismo: coincidir, companhia e assim por diante. Para entender melhor, podemos nos remeter ao primeiro exemplo que ela dá:

\footnotetext{
"Se for necessário um traço distintivo de nossa experiência do real, seja ela próxima ou longínqua, podemos partir de seu alto nível de midiatização pelas telas de computadores ou aparelhos de TV. Vivemos de maneira intensa na companhia de telas pequenas, as quais descarregam em nossa sala, nossos quartos e nossos locais de trabalho um volume considerável de informações e/ou tolices sobre o mundo; no entanto, não ficamos aturdidos por isso, não somos engolidos pelas telas de tevê ou computador, só lhes cedemos uma fração limitada de nossa atenção - esse é o segundo traço distintivo. Nossas telas não são como a tela de cinema; em frente a uma tela pequena ou média da qual somos, em certa medida, o projecionista, quase não nos esquecemos de nós mesmos, comentamos em voz alta o espetáculo enquanto ele se desenrola diante de nós, trocamos o DVD, apertamos botões, comemos um sanduíche, atendemos ao telefone." (grifo nosso)
}

Essa postura é contemporânea no terceiro sentido da palavra. Ela sustenta um "comércio" (o termo irônico empregado por Pireyre) com o tempo, sem aceitar a lógica da alienação nem da oposição, tão cara aos teóricos modernistas. Todavia, nesse "comércio contínuo que nos entretém com nossas telas por companhia”, afirma ela, "quase todas as 
frases vêm de um mundo que deve ser, portanto, tomado com suspeita. De um lado, o mundo se torna mais forte, embora essa chuva de informações entre na massa de nosso interior; porém, de outro lado, essas milhares de informações não são fornecidas de maneira bruta e são impróprias para a absorção imediata, pois são embaladas; o desembalamento de pacotes constitui boa parte de nossas atividades de escritura". Retornando à sua proposição inicial, ela afirma:

\footnotetext{
“Essa singularidade não está em relação de oposição frontal com o grupo social, como costuma ser o caso nos romances, da poesia lírica, do cinema de ficção, nos quais as aspirações particulares de um ser, sua própria poesia, se chocam com os imperativos prosaicos, com a lei e com as regras gerais do grupo; a singularidade tem sua direção desviada do interior das línguas de autoridade, fazendo-as destoar por justaposição e agir umas contra as outras.

O interesse reside precisamente no equívoco."
}

Eis o equívoco como outro nome de companheirismo do tempo, pois, vale dizer, renunciar à postura contrária não significa absolutamente consentir ou seguir de maneira cega. Tampouco tornar a se fechar em um tipo de poética, seja ela tecnófila ou experimental. Não se trata, portanto, de um manifesto de poesia experimental, mas sim de um manifesto do cum-, um manual de sobrevivência no companheirismo que abstrai a lógica oposicional. Vemos que ser com o tempo, ser camarada do tempo, é seguir a corrente, ocupá-la, habitá-la, para então reconfigurá-la e fazê-la ver. A conclusão da autora é clara:

\footnotetext{
"Por fim, do ponto de vista gramatical, parece que tudo isso também poderia se traduzir em um novo emprego do plural. Se a relação com o mundo não é um antagonismo franco do Eu com o exterior real, mas antes um seguimento e um movimento do Eu no seio dos acontecimentos e do discurso social, com o desejo de imitá-los, de reconfigurá-los, de confrontá-los a partir de seu interior, de torná-los habitávels, a atenção então passa para o plural, para as construções sociais, as extensões de Nós em diversas dimensões.”
}

Esse postulado não é de modo algum isolado. Muito pelo contrário. 


\begin{tabular}{l|ll}
\hline celeuma & número 4 | maio 2014 & dossiê \\
\hline
\end{tabular}

Deixemos a literatura francesa e nos voltemos para um best-seller internacional. Gomorra, de Roberto Saviano, propõe uma postura parecida, especialmente na grande passagem metatextual do livro em que o autor confronta o romancista naturalista social Luciano Bianciardi e Pier Paolo Pasolini. Finado o escritor-terrorista, como o primeiro, e findo o escritor-aventureiro, como o segundo, vemos agora o escritor embarcado, embedded, imerso no real, sobre o qual ele não tem qualquer discurso prévio, mas apenas provas que combina e torna visíveis. Podemos encontrar múltiplos exemplos nas literaturas ou nas práticas artísticas que transformaram sua contextualização em provas [6], seja na prosa do mundo ou em suas respostas concretas.

Há nessa postura e nessa prática algo de composicionismo, outro termo formado com a raiz cum-, caro a Bruno Latour; esse composicionismo, de um lado, se distingue (claramente) da lógica oposicional, mas, de outro, formula uma das raríssimas proposições de ataque à modernidade e ao moderno (como pensa o próprio Jauss). Contudo, Latour se diverte em seu manifesto composicionista com os próprio signos do modernismo, plagiando, à sua maneira, os mais célebres dentre eles: "A specter haunts not only Europe but the world: that of compositionism. All the Powers of the Modernist World have entered into a holy alliance to exorcise this specter!". [7] Mas ele se distingue ao excluir seu manifesto de seu ambiente habitual. "Actually, it is the time of time that has passed." Um tempo dirigido inevitavelmente para a frente, de maneira irreversível, guiado por uma elite esclarecida que escreve manifestos para ganhar essa luta pelo progresso. Por mais que eu tenda a achar que a justificativa desse manifesto está anotada ("one has to accept to live with contradictions...", p. 488), Latour deseja impor uma diferença entre manifestos modernos e seu manifesto composicionista: "The nuance I want to outline is that between progress and progressive. It is as if we had to move from an idea of inevitable progress to one of tentative and precautionary progression" (473).

Mas a palavra manifesto interessa menos à semantização da palavra contemporâneo (ainda que tornar manifesto seja atualizar e tornar presente) do que a palavra composicionista, ainda mais no primeiro sentido que Latour lhe confere, como uma alternativa à crítica, que ecoa, 


\begin{tabular}{l|ll}
\hline celeuma & número 4 | maio 2014 & dossiê \\
\hline
\end{tabular}

a meu ver, a problematização da lógica oposicional entendida na palavra contemporâneo. Como se trata de áreas delicadas (uma crítica à crítica?), não é preciso caricaturar seu pensamento. Latour é muito claro sobre o sentido dado à palavra crítica: “Critique' is taken here in the meaning of the word introduced by Immanuel Kant, that is, a wholesale acceptation of the divide between human and nonhuman, not in the rather ubiquitous skill of having a critical mind" (488). Não se trata de uma crítica à crítica, mas, ao contrário, de um novo uso da crítica. $\mathrm{O}$ mundo da crítica jaz na ideia essencial de que existe uma divisão, senão uma oposição, entre o mundo da realidade e o das aparências. A crítica serviria para transpor esse muro das aparências. "Critique, in other words, has all the limits of utopia: it relies on the certainty of the world beyond this world. By contrast, for compositionism, there is no world of beyond. It is all about immanence" (475). A lógica composicionista, ao suspender o gesto crítico, decompõe e recompõe peça por peça. "We compositionists want immanence and truth together. Or, to use my language: we want matters of concern, not only matters of fact. For a compositionist, nothing is beyond dispute. And yet, closure has to be achieved. But it is achieved only by the slow process of composition and compromise, not by the revelation of the world of beyond" (478). Encontramos formulações muito próximas às de Emmanuelle Pireyre quando Latour exprime o seguinte desejo: "We need to have a much more material, much more mundane, much more immanent, much more realistic, much more embodied definition of the material world if we wish to compose a common world" (484). É uma visão muito boa da terceira semantização da palavra contemporâneo. Para compor um mundo comum, é preciso um certo companheirismo do tempo. $\mathrm{O}$ companheirismo do tempo compõe o mundo comum.

\section{UMA ARQUEOLOGIA DO CONTEMPORÂNEO}

Uma story, quatro abordagens, muitas hipóteses, três significações - isso é sem dúvida muito. Contudo, tenho certeza de que, quando usamos esse termo, é o conjunto de suas potencialidades que é convocado, com maior ou menor grau de intensidade. É a pluralidade quase infinita de usos da palavra que, por si só, é realmente significativa. Como então não se deixar tragar por um tema tão multiforme? Nas ciências humanas, propôs-se uma abordagem que é um instrumento da pluralidade - trata- 
se da arqueologia; mais precisamente, da arqueologia do saber.

Já há mais de quarenta anos, essa palavra, arqueologia, ficou famosa e é difícil saber se é metafórica ou se designa um método real de investigação. Aqueles que a usam, como eu, o fazem em referência ao livro fascinante de Michel Foucalt, $A$ arqueologia do saber, publicado em 1969. O livro fascina porque sua densidade e seu nível de abstração teórica são tamanhos que costuma ser evitado. Há quem prefira um livro mais "encorpado", como As palavras e as coisas, cujo subtítulo é "Uma arqueologia das ciências humanas". Sua introdução abandona a compreensão que podemos ter disso:

\footnotetext{
Tal análise, como se vê, não compete à história das idéias ou das ciências: é antes um estudo que se esforça por encontrar a partir de quê foram possíveis conhecimentos e teorias; a partir de qual espaço de ordem se constituiu o saber; na base de qual a priori histórico e no elemento de qual positividade puderam aparecer idéias, se constituírem as ciências, se refletirem experiências em filosofias, formar-se racionalidades, para talvez se desarticularem e logo desvanecerem. Não se tratará, portanto, de conhecimentos descritos no seu progresso em direção a uma objetividade na qual nossa ciência de hoje pudesse enfim se reconhecer; o que se quer trazer à luz é o campo epistemológico, a epistémê onde os conhecimentos, encarados fora de qualquer critério referente a seu valor racional ou a suas formas objetivas, enraízam sua positividade e manifestam assim uma história que não é a de sua perfeição crescente, mas, antes, a de suas condições de possibilidade; neste relato, o que deve aparecer são, no espaço do saber, as configurações que deram lugar às formas diversas do conhecimento empírico. Mais que de uma história no sentido tradicional da palavra, trata-se de uma “arqueologia”.[8]
}

Essa passagem, extremamente famosa, foi escrita em outro contexto, outro tempo, em que era necessário se opor a uma visão contínua e linear da história. Sem dúvida, a disciplina histórica, que Michel Foulcault já reconhecia que não deveria ser caricaturada, após 40 anos evoluiu profundamente no sentido dessa arqueologia, e o corpus de escritos sobre as invenções são provas disso. Contudo, face à tentação de escrever 
uma história unívoca do contemporâneo, a arqueologia foucaltiana ainda parece de uma ajuda inestimável.

Já no ensaio que eu propunha, ao me interessar mais pelos usos do que pelas essências, supus que o contemporâneo fosse, antes de tudo, um evento de discurso. O mundo não mudou por causa de tal e tal evento que nos teria tornado contemporâneos ao passo que antes éramos... o que mesmo? Modernos? Modernistas? Pós-modernos? O "contemporâneo" é, antes de tudo, falado em formações discursivas diversas: discursos disciplinares, discursos midiáticos, discursos domésticos, discursos profissionais. É impressionante constatar como uma palavra pode se difundir imediatamente, contaminando certos estratos de discursos, ao passo que outras não. É importante, por isso, observar essa contaminação como um evento sempre recomeçado e realizado. Ele surge em certas áres institucionais, práticas, materiais e linguísticas. Liga-se a outras ou permite a ligação entre conjuntos discursivos diferentes nos quais pode significar uma coisa diferente a cada vez. Os discursos são feitos de séries, descontinuidades, retomadas e rupturas que acabam constituindo uma coerência. Essa coerência, em nosso caso, poderia ser chamada de contemporaneísmo, o conjunto difuso, difratado e plural de discursos que qualificam uma experiência temporal de contemporânea.

É isso que podemos entender a partir do questionamento sobre o contemporâneo. Nenhuma contribuição a esse debate nocional, nem mesmo a de Giorgio Agamben,[9] pareceu suficientemente sólida para se impor. Contudo, não faltam autoridades nesse debate, seja nas práticas artísticas e curatoriais, seja nas ciências sociais ou humanas. Mas nenhuma encerra o movimento, nem mesmo por um tempo. É difícil imaginar, para tomar um exemplo ainda recente e bem pouco autoritário, um coletivo escrever O que é a filosofia? em 1992 e 1993 logo após o de Deleuze e Guattari[10]. Queiramos ou não, por sua própria empreitada, Deleuze e Guattari, talvez exatamente por serem quem são, fixaram os termos do debate sobre a questão. Mas, ao que parece, essa foi a última vez em que isso aconteceu.

As regras mudaram muito desde então. Não seria certo, nestas 
condições, acreditar que a resposta à questão "O que é o contemporâneo?” ainda esteja ausente, à espera de seu exegeta, de seu especialista ou profeta. A resposta à pergunta "O que é o contemporâneo?” existe, está diante dos nossos olhos, visível - basta ficar atento e dar ouvidos a ela.

Ela está nessa multiplicidade não resolvida, nesse zum-zum-zum que ressoa em todo o mundo e graças ao qual aqueles que aparentemente não dialogam acabam por dialogar. Essa visão, exposta nesses termos, poderia parecer angelical. Mas não é, pois a multiplicidade não resolvida que ela evoca é naturalmente agonística. Ela comprova uma democratização de discursos, o reequilíbrio geográfico de seus usos, as descentralizações institucionais próprias ao contemporâneo, ao mesmo tempo em que se impõe como experiência concreta dessa multiplicidade de narrativas mais ou menos oposicionais. Essa experiência é também a da pluralização de espaços públicos dialógicos onde essas narrativas se formam e se exprimem.

A história nocional e institucional do contemporâneo também é, em grande medida, agonística, sendo produto de discussões e controvérsias, mal-entendidos e desacordos. A imposição desse conceito, por exemplo, na instituição dos museus, à qual sem dúvida deve seu triunfo atual, tem duas origens em grande medida opostas: uma mais conservadora e antimoderna, e outra que desconstrói a narrativa moderna e inventa um novo espaço público da arte. Os valores que essa divergência expressou ilustram nossa compreensão do conceito. Mais impressionante ainda, a própria palavra "contemporâneo" não significa a mesma coisa para historiadores, filósofos, especialistas em estética ou artistas. Existem abordagens disciplinares do contemporâneo que problematizam sua utilização no singular.

Por outro lado, os momentos de maior consciência histórica, de construção do presente, de contemporaneização (na Europa, o Renascimento, o Iluminismo, a modernidade, entre outros), quando observados de perto, nos parecem múltiplos e contraditórios, ruidosos e oposicionais. Mais uma vez o zum-zum-zum. Foi apenas a sua classificação histórica e sua patrimonialização que os disciplinaram. 
Nesse sentido, o zum-zum-zum oferece o sentido filosófico, estético e político do contemporâneo, seja ele considerado de maneira epocal (como nossa época), modal (como um modo de ser histórico) ou nocional (disciplinar e institucional). Há muito disciplinado, ele se impõe agora como marcador histórico do nosso tempo e como modo de releitura da história. Se existe, portanto, uma diferença da época chamada de contemporânea em relação às outras épocas contemporâneas, reconhecemos deliberadamente que não é apenas o zum-zum-zum que a caracteriza, mas principalmente o que caracterizou o presente, cuja definição forma um campo de batalha ininterrupto. Mas esse não é um zum-zum-zum qualquer. Em cada época, não são as mesmas pessoas que falam, nos mesmos lugares, sobre os mesmos temas, com as mesmas consequências possíveis. As diferenças históricas dependem essencialmente dessas variações, que relevam a configuração das esferas públicas. Participar da elaboração do presente é, na verdade, um privilégio que mudou com o tempo.

Esse reconhecimento impõe um problema para o ensaísta que busca falar dele. Como dar conta do zum-zum-zum sem discipliná-lo e sem se deixar levar por ele? Afinal, se rejeito as stories ordenadas demais, me parece impossível abordar essa multiplicidade de frente e ainda mais impossível fazer com que os leitores vejam, entendam, percebam ou compreendam. A multiplicidade exige uma estratégia.

Nada me pareceu mais próximo de um evento de discurso do que os momentos que constituem o contemporâneo na enunciação da pergunta: “O que é o contemporâneo?”. A partir de todas as evidências (repetição e concentração em determinado período), trata-se de uma série. Mas é uma série que se caracteriza por sua diferença ou diversidade. Podemos, então, interrogar seus princípios. Investigar especialmente a identidade daqueles que, há menos de dez meses, colocam essa questão; sobre os lugares (territoriais, disciplinares, profissionais) em que atuam, e os regimes epistemológicos e discursivos que eles utilizam.

Essa é a porta de entrada, que serve de trama e quase de cenário para meu estudo[11], permitindo que sigamos a mesma rota de Rosario em Stanford, de um centro de arte contemporânea provinciano a um dos 
centros do mundo acadêmico, pois, graças ao poder arquivístico das novas tecnologias, basta inserir esta simples pergunta, “¿Qué es lo contemporáneo?” que, zum, uma reflexão local se encontra na origem de uma interrogação quase global que nos leva à Itália, à França, ao Reino Unido, aos Estados Unidos, à China, a Nova Deli, a Hong Kong, ao Chile, à Bélgica, à Escócia. E algum estudante de comunicação ou aspirante a artista ou pensador se meterá a dialogar com Giorgio Agamben, Nancy Frase, Hans Ulrich Obrist, Donna Haraway, Okwui Enwezor, Gayatri Chakravorty Spivak, Ravi Sundaram, Raqs Media Collective, Stuart Hall, Pascal Quignard ou Hayden White. A story se contentaria em utilizar o livro de Giorgio Agamben, consagrando-o como a palavra definitiva, ao mesmo tempo retrospectiva e profética, e analisaria os fenômenos da contemporaneidade a partir dele. As diversas razões para essa tendência incluem: é um livro (mais prático e sério do que uma obra radiofônica ou um fanzine virtual) de um autor único (menos difícil de analisar do que uma obra coletiva), mundialmente conhecido e traduzido em várias línguas. A investigação arqueológica faria uma coisa completamente diferente. Claro, ela levaria em conta esse livro. Mas o introduziria em uma série e observaria as condições que possibilitaram sua existência, colocando-o como um elemento em um meio mais amplo. No fundo, essa diferença lembra a feita também por Michel Foucaul entre história global e história geral.

\footnotetext{
Uma descrição global cinge todos os fenômenos em torno de um centro único - princípio, significação, espírito, visão do mundo, forma de conjunto; uma história geral desdobraria, ao contrário, o espaço de uma dispersão. [12]
}

Portanto, minha estratégia é simples: considerando que, assim como todos os conceitos e noções que utilizamos, o contemporâneo foi objeto de uma invenção e de uma fabricação, busco voltar a essa invenção indo atrás de um de seus momentos emblemáticos: a questão "O que é o contemporâneo?", sejam quais foram os autores que a colocaram, os lugares a partir de onde foi colocada ou as condições em que foi colocada. Feito isso, um arquivo do contemporâneo se atualiza. 


\begin{tabular}{l|l|l|l|}
\hline celeuna & número 4 maio 2014 \\
\hline
\end{tabular}

[1]Lionel Ruffel, "Qu'est-ce que le contemporain? Une introduction”, em Lionel Ruffel (org.) Qu'est-ce que le contemporain?, Nantes, Cécile Defaut Éditions, 2010. [2] H. R. Jauss, "Modernity and literary tradition", trad. Christian Thorne, Critical Inquiry 31 (inverno de 2005), pp. 329-64.

[3] Uso aqui as categorias de Vincent Descombes ao mesmo tempo em que me desvio delas. "Do ponto de vista dos filósofos", escreve Descombes, "existe pelo menos dois grandes conceitos possíveis do contemporâneo. A primeira concepção é fornecida pela filosofia da história. Ela entra aqui como nos programas de história que incluem, em uma primeira parte, o estudo da época moderna e contemporânea: o 'mundo contemporâneo' aparece como um ponto avançado do 'mundo moderno' (...) Na concepção epocal, a contemporaneidade é tratada como uma concidadania de uma época; assim como os compatriotas são de um mesmo país, os contemporâneos são de um mesmo tempo histórico (...) A segunda concepção é gerada por uma reflexão sobre a ideia de tempo. Se procurarmos uma noção de contemporâneo numa filosofia do tempo, conceberemos o contemporâneo como um concurso entre muitas mudanças atuais. Ser contemporâneos significará compartilhar a mesma atualidade histórica. Ou, então, o conceito de atualidade é um conceito modal: o atual é definido através do contraste com o potencial ou o possível (...) A atualidade não é acima de tudo aquilo que é tratado nos jornais, mas sim o que se produz efetivamente e que nos afeta agora, mesmo que os jornais não tratem disso. Considerando o papel representado pela noção de atualidade nessa segunda concepção de contemporâneo, podemos falar de uma compreensão modal em oposição à compreensão epocal". Utilizo essas duas noções de maneira simplista. A concepção epocal designa as abordagens que insistem no nosso tempo histórico e naquilo que o distingue dos demais. A concepção modal é vista como uma dada relação com a história e a atualidade. Ver Vincent Descombes, "Qu'est-ce qu'être contemporain?”, em Le Genre humain, “Actualités du contemporain”, nº 35, 2000, pp. 20-32.

[4] François Hartog, Régimes d'historicité. Présentisme et expérience du temps. Paris: Seuil, coll. La librairie du XXIe siècle, 2003, p. 28.

[5] Emmanuelle Pireyre, "Fictions documentaires", em (coletivo) Devenirs du roman, Paris, Naïve, 2006.

[6] David Ruffel, “Une littérature contextuelle”, em Littérature n¹60 (4/2010), "La littérature exposée: les écritures contemporaines hors du livre”, Paris, Larousse.

[7] Bruno Latour, “An Attempt at a 'Compositionist Manifesto", New Literary History, 2010, 41, p. 473.

[8] Michel Foucaul, As palavras e as coisas. São Paulo, Martins Fontes, 2000.

[9] Giorgio Agamben, Che cos'è il contemporaneo? Roma, Nottetempo, 2008.

[10] Gilles Deleuze ee Félix Guattari, Qu'est-ce que la philosophie?, Paris, Minuit, 1991.

[11] Esse estudo foi publicado em inglês em uma versão muito condensada e narrativa na Revista de Estudios Hispánicos (48. 1) e, em francês, em uma versão longa e teórica pela Edições De la Découverte.

\footnotetext{
LIONEL RUFFel é professor da Universidade Paris 8/Instituto Universitário da França e organizador de Qu'est-ce que le contemporain?(Cécile Defaut Éditions)
} 